\title{
Novel biocatalyst for efficient synthesis of catecholic polyphenol products
}

\author{
Yi-Xiong Wei ${ }^{\dagger}$, Chun-Mei Wei ${ }^{\ddagger}$, Shuangfei $\mathrm{Li}^{\dagger}$, Yong Zou ${ }^{\S}$, Zhen Yang ${ }^{\star *}$
}

†College of Life Sciences and Oceanography, Shenzhen Key Laboratory of Marine Bioresources and Ecology, Shenzhen University, Shenzhen, Guangdong 518055, China.

College of Life Sciences and Oceanography, Shenzhen Key Laboratory of Microbial Genetic Engineering, Shenzhen University, Shenzhen, Guangdong 518055, China.

${ }^{\S}$ School of Pharmaceutical Sciences, Sun Yat-Sen University, Guangzhou, Guangdong 510006, China.

*Corresponding author: Zhen Yang, Ph.D., Professor

Address: College of Life Sciences and Oceanography, Shenzhen University, 1066 Xue Yuan Avenue, Shenzhen, Guangdong 518055, China.

E-mail: zyang@szu.edu.cn

Number of pages: 4

Number of figures: 3

Number of tables: 1 
Fig. S1 HPLC and TLC chromatograms of samples from the two synthetic reactions: resveratrol $\rightarrow$ piceatannol (A \& C), L-tyrosine $\rightarrow$ L-DOPA (B \& D)

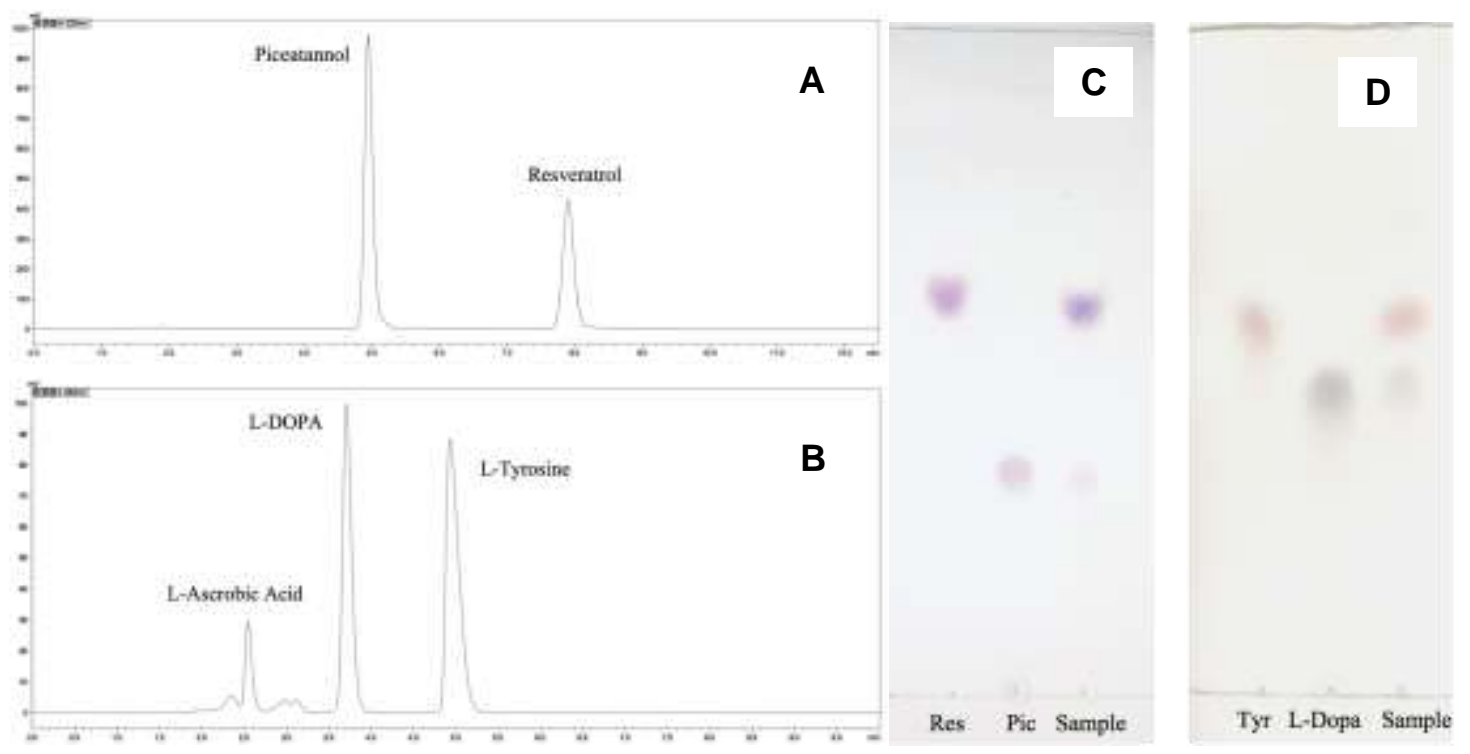

Fig. S2 Effects of pH (A), temperature (B), L-ascorbic acid (C) and EDTA (D) on TCHC-catalyzed ortho-hydroxylation of L-tyrosine to produce L-DOPA
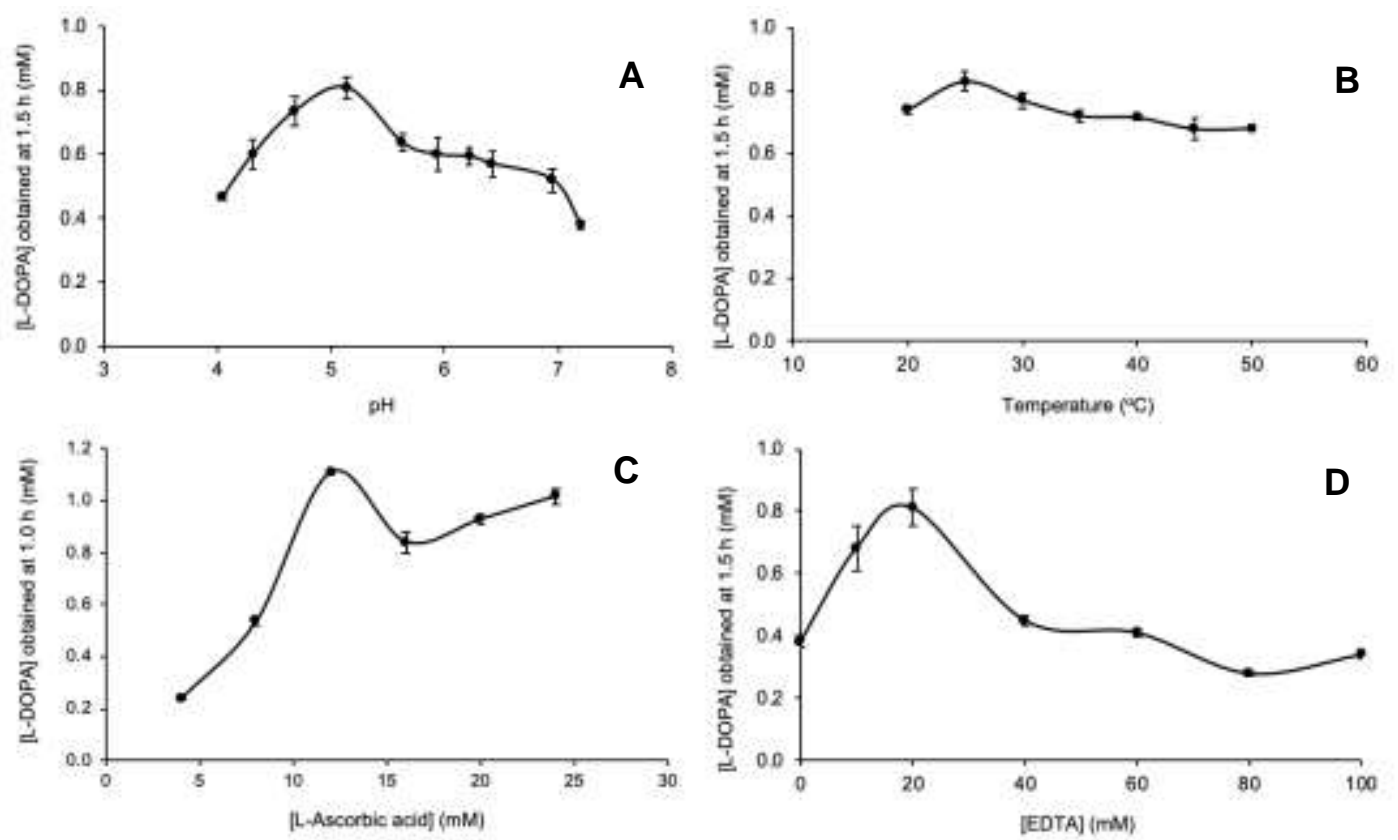
Fig. S3 Stability of the free enzyme, TCHCs and TCHC-Cu alginate beads at $60{ }^{\circ} \mathrm{C}$

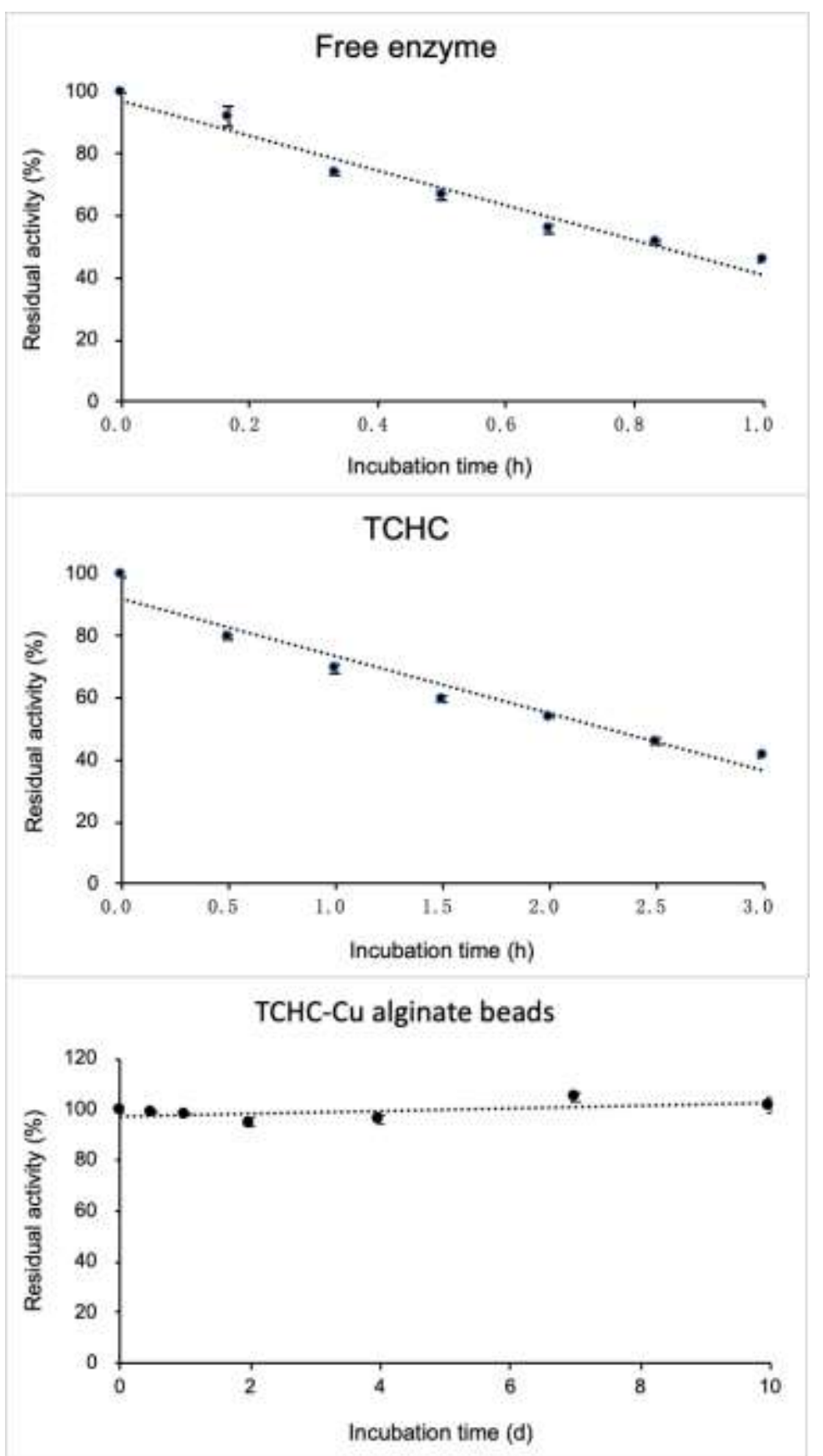

Enzyme samples were incubated in phosphate buffer $(50 \mathrm{mM}, \mathrm{pH} 6.0)\left(2.0 \mathrm{~mL}\right.$ each) at $60{ }^{\circ} \mathrm{C}$. Periodically, the enzyme sample was transferred to $8.0 \mathrm{~mL}$ substrate solution containing L-tyrosine, EDTA (for TCHCs only), and L-ascorbic acid (their final concentrations in the $10.0 \mathrm{~mL}$ reaction systems were $2.0 \mathrm{mM}, 20 \mathrm{mM}, 12 \mathrm{mM}$, respectively) to start the reaction at $25{ }^{\circ} \mathrm{C}$ for $30 \mathrm{~min}$. The concentrations of the L-DOPA obtained was determined by using HPLC, and the time-dependent loss in this [L-DOPA] was used to calculate the half-life for each enzyme sample. 
Table S1. Variables and levels used for the Box-Behnken design to prepare TCHCs

\begin{tabular}{ccccc}
\hline \multirow{2}{*}{ Variable } & \multirow{2}{*}{ Symbol } & \multicolumn{3}{c}{ Level } \\
\cline { 3 - 5 } & & -1 & 0 & +1 \\
\hline $\mathrm{CuSO}_{4}$ concentration $(\mathrm{mM})^{\mathrm{a}}$ & $\mathrm{A}$ & 5 & 10 & 15 \\
\hline${\mathrm{PBS} \text { concentration }(\mathrm{mM})^{\mathrm{a}}}^{2}$ & $\mathrm{~B}$ & 0 & $10^{\mathrm{b}}$ & $20^{\mathrm{b}}$ \\
\hline Reaction time (day) & $\mathrm{C}$ & 2 & 3 & 4 \\
\hline
\end{tabular}

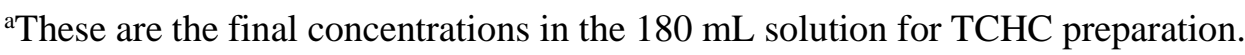

bPhosphate buffer saline (PBS) normally contains $\mathrm{NaCl}(137 \mathrm{mM}), \mathrm{KCl}(2.7 \mathrm{mM}), \mathrm{Na}_{2} \mathrm{HPO}_{4}(10 \mathrm{mM})$ and $\mathrm{KH}_{2} \mathrm{PO}_{4}(1.8 \mathrm{mM}) .10$ or $20 \mathrm{mM}$ in this table refers to the concentration of $\mathrm{Na}_{2} \mathrm{HPO}_{4}$ used in the PBS, and the concentrations for the other three components in the PBS are varied accordingly following the recipe of the conventional PBS. 